\title{
Uncertain Linguistic Aggregation Distance Measures and Their Application to Group Decision Making
}

\author{
Wei $\mathrm{Li}^{1}$ and Shouzhen Zeng ${ }^{2}$ \\ ${ }^{1}$ College of Mathematics and Statistics, Zhejiang University of Finance and Economics, Hangzhou 310018, China \\ ${ }^{2}$ College of Computer and Information, Zhejiang Wanli University, Ningbo 315100, China \\ Correspondence should be addressed to Shouzhen Zeng; zszzxl@163.com
}

Received 3 April 2013; Accepted 10 July 2013

Academic Editor: Luca Formaggia

Copyright (c) $2013 \mathrm{~W}$. Li and S. Zeng. This is an open access article distributed under the Creative Commons Attribution License, which permits unrestricted use, distribution, and reproduction in any medium, provided the original work is properly cited.

\begin{abstract}
We introduce a method based on distance measures for group decision making under uncertain linguistic environment. We develop some uncertain linguistic aggregation distance measures called the uncertain linguistic weighted distance (ULWD) measure, the uncertain linguistic ordered weighted distance (ULOWD) measure, and the uncertain linguistic hybrid weighted distance (ULHWD) measure. We study some of their characteristic, and we prove that the ULWD and the ULOWD are special cases of the ULHWD measure. Finally, we develop an application of the ULHWD measure in a group decision making problem concerning the evaluation of university faculty for tenure and promotion with uncertain linguistic information.
\end{abstract}

\section{Introduction}

As a common tool for measuring the deviations of different arguments, distance measures are fundamentally important in a variety of scientific fields such as decision making, pattern recognition, machine learning, and market prediction. A variety of distance measures have been introduced and investigated in the past several decades [1-11]. Most existing distance measures are the weighted distance measures, including some well-known distance measures such as the weighted Hamming distance and the weighted Euclidean distance. One problem of these distance measures is that they take the importance of the given individual distances into consideration, and then aggregate the difference elements together with their weights. Recently, motivated by the idea of the ordered weighted averaging (OWA) operator [12], Xu and Chen [13] introduced the ordered weighted distance (OWD) measure, which emphasizes the importance of the ordered position of the given individual distances instead of weighting arguments themselves. The prominent characteristic of the OWD is that it can relieve (or intensify) the influence of unduly large or unduly small deviations on the aggregation results by assigning them low (or high) weights. This desirable characteristic makes the OWD very useful in many actual fields such as group decision making, medical diagnosis, data mining, and pattern recognition. Since it was introduced, the OWD has been studied by many authors. Yager [14] generalized the OWD and provided a variety of ordered weighted averaging norms, based on which he proposed several similarity measures. Merigó and Gil-Lafuente [15] introduced an ordered weighted averaging distance (OWAD) operator and gave its application in the selection of financial products. The OWD measures are generally used to deal with situations where the input data are expressed in exact numerical values. Zeng and Su [16] extended the OWD to uncertain situation with intuitionistic fuzzy information [17] and developed an intuitionistic fuzzy OWD (IFOWD) operator. Zeng [18] developed some intuitionistic fuzzy aggregation distance measures, such as the intuitionistic fuzzy ordered weighted distance (IFOWD) measure, interval-valued intuitionistic fuzzy ordered weighted distance (IVIFOWD) measure, intuitionistic fuzzy hybrid weighted distance (IFHWD) measure, and interval-valued intuitionistic fuzzy hybrid weighted distance (IVIFHWD) measure and applied them to group decision making. Xu [19] developed some fuzzy ordered distance measures, including linguistic ordered weighted distance measure, uncertain ordered weighted distance measure, linguistic hybrid weighted distance measure, and uncertain 
hybrid weighted distance measure. For further research on the use of the OWA operator in distance measures, see, for example, [10, 20-23].

In many complicated practical situations, the decision makers are willing or able to provide only uncertain linguistic information because of time pressure, lack of knowledge, or data, and their limited expertise related to the problem domain [24-28]. Therefore, it is necessary to pay attention to this issue. In this paper, we will develop some uncertain linguistic aggregation distance measures including the uncertain linguistic weighted distance (ULWD), the uncertain linguistic ordered weighted distance (ULOWD) measure, and uncertain linguistic hybrid weighted distance (ULHWD) measure. The fundamental aspect of the ULWD measure is that it only takes the importance of the given individual distances into consideration, and then aggregates these difference elements together with their weights. The ULOWD and ULHWD measures are extensions of the OWD with uncertain linguistic variables. The main advantage of the ULOWD and ULHWD is that they can alleviate the influence of unduly large (or small) deviations on the aggregation results by assigning them low (or high) weights. We have proved that the ULWD and the ULOWD are specials of the ULHWD measure. Moreover, we will apply the ULHWD measure to group decision making with uncertain linguistic information.

This paper is organized as follows. In Section 2, we briefly describe some basic aggregation operators and distance measures. In Section 3, we introduce the uncertain linguistic variables and the ULWD measure. In Section 4, we present the ULOWD and ULHWD measure in Section 5. In Section 6, we briefly describe the decision making process based on the ULHWD measure and we give a numerical example in Section 7. Section 8 summarizes the main conclusions of the paper.

\section{Preliminaries}

In this section we briefly review some basic distance measures, the OWA operator and the OWD measure.

Among the existing weighted distance measures, the weighted Hamming distance and the weighted Euclidean distance are the two most widely used ones, which can be described as follows.

Let $\alpha=\left(\alpha_{1}, \alpha_{2}, \ldots, \alpha_{n}\right)$ and $\beta=\left(\beta_{1}, \beta_{2}, \ldots, \beta_{n}\right)$ be two collections of real numbers, and let $w=\left(w_{1}, w_{2}, \ldots, w_{n}\right)$ be the weighting vector of the absolute difference $\left|\alpha_{j}-\beta_{j}\right|(j=$ $1,2, \ldots, n)$, where $w_{j} \in[0,1]$ and $\sum_{j=1}^{n} w_{j}=1$, then

(1) the weighted Hamming distance measure is

$$
\operatorname{WHD}(\alpha, \beta)=\sum_{j=1}^{n} w_{i}\left|\alpha_{j}-\beta_{j}\right|
$$

(2) the weighted Euclidean distance is

$$
\operatorname{WED}(\alpha, \beta)=\sqrt{\sum_{j=1}^{n} w_{i}\left(\alpha_{j}-\beta_{j}\right)^{2}} .
$$

Obviously, the above two weighted distance measures only take the importance of each difference element of data into consideration and then aggregate the difference elements together with their weights.

The ordered weighted averaging (OWA) operator introduced by Yager [12] provides a parameterized family of aggregation operators that include the maximum, the minimum, and the average criteria. The fundamental aspect of the OWA operator is the reordering step: it first reorders all the given arguments in descending order and then weights these ordered arguments and finally aggregates all these ordered weighted arguments into a collective one. Since its appearance, the OWA operator has been studied in a wide range of studies [29-44]. It can be defined as follows.

Definition 1. An OWA operator of dimension $n$ is a mapping OWA: $R^{n} \rightarrow R$, which has an associated weighting $W$ with $w_{j} \in[0,1]$ and $\sum_{j=1}^{n} w_{j}=1$, such that:

$$
\operatorname{OWA}\left(a_{1}, \ldots, a_{n}\right)=\sum_{j=1}^{n} w_{j} b_{j},
$$

where $b_{j}$ is the $j$ th largest of the $a_{i}$.

Recently, motivated by the idea of the OWA operator, $\mathrm{Xu}$ and Chen [13] developed an ordered weighted distance measure (OWD).

Definition 2. Let $\alpha=\left(\alpha_{1}, \alpha_{2}, \ldots, \alpha_{n}\right)$ and $\beta=\left(\beta_{1}, \beta_{2}, \ldots, \beta_{n}\right)$ be two collections of real numbers, and let $d\left(\alpha_{j}, \beta_{j}\right)=\left|\alpha_{j}-\beta_{j}\right|$ be the distance between $\alpha_{j}$ and $\beta_{j}$, then

$$
\operatorname{OWD}(\alpha, \beta)=\left(\sum_{j=1}^{n} w_{j}\left(d\left(\alpha_{\sigma(j)}, \beta_{\sigma(j)}\right)\right)^{\lambda}\right)^{1 / \lambda}
$$

is called an ordered weighted distance (OWD) between $\alpha$ and $\beta$, where $\lambda>0,(\sigma(1), \sigma(2), \ldots, \sigma(n))$ is any permutation of $(1,2, \ldots, n)$, such that

$$
d\left(\alpha_{\sigma(j-1)}, \beta_{\sigma(j-1)}\right) \geq d\left(\alpha_{\sigma(j)}, \beta_{\sigma(j)}\right), \quad j=1,2, \ldots, n
$$

and $w=\left(w_{1}, w_{2}, \ldots, w_{n}\right)$ be the weight vector of the absolute difference $\left|\alpha_{j}-\beta_{j}\right|(j=1,2, \ldots, n)$, where $w_{j} \in[0,1]$ and $\sum_{j=1}^{n} w_{j}=1$.

Especially, if $\lambda=1$, then the OWD measure is called an ordered weighted Hamming distance (OWHD) measure:

$$
\operatorname{OWHD}(\alpha, \beta)=\sum_{j=1}^{n} w_{j} d\left(\alpha_{\sigma(j)}, \beta_{\sigma(j)}\right) \text {. }
$$

In the case of $\lambda=2$, then the OWD measure is reduced to the ordered weighted Euclidean distance (OWED) measure:

$$
\operatorname{OWED}(\alpha, \beta)=\left(\sum_{j=1}^{n} w_{j}\left(d\left(\alpha_{\sigma(j)}, \beta_{\sigma(j)}\right)\right)^{2}\right)^{1 / 2}
$$

The OWD measure is very suitable to be used in many actual fields, including group decision making, medical diagnosis, data mining, and pattern recognition $[13,18]$. However, 
the OWD measure is mainly used to aggregate or measure the data taking the form of exact numerical; in what follows, we extend the OWD to accommodate the situation in which the input data is provided with uncertain linguistic information.

\section{Uncertain Linguistic Variables and Uncertain Linguistic Weighted Distance (ULWD) Measure}

The linguistic approach is an approximate technique which represents qualitative aspects as linguistic values by means of linguistic variables $[8,24,45,46]$. Suppose that $S=\left\{s_{\alpha} \mid\right.$ $\alpha=-t, \ldots, 0,1, \ldots, t\}$ is a finite and totally ordered discrete term set, where $s_{\alpha}$ represents a possible value for a linguistic variable. For example, a set of nine terms $S$ could be define as

$$
\begin{aligned}
S=\left\{s_{-4}\right. & =\text { extremely poor, } s_{-3}=\text { very poor, } \\
s_{-2} & =\text { poor, } s_{-1}=\text { slightly poor, } \\
s_{0} & =\text { fair, } s_{1}=\text { slightly good, } s_{2}=\text { good, } \\
s_{3} & \left.=\text { very good, } s_{4}=\text { extremely good }\right\} .
\end{aligned}
$$

To preserve all the given information, $\mathrm{Xu}$ [8] extended the discrete term set $S$ to a continuous term set $\bar{S}=\left\{s_{\alpha} \mid\right.$ $\alpha \in[-t, t]\}$, whose elements also meet all the characteristics above, and where, if $s_{\alpha} \in S$, then we call $s_{\alpha}$ the original term, otherwise, we call $s_{\alpha}$ the virtual term; In general, the decision maker uses the original linguistic terms to evaluate alternatives, and the virtual linguistic terms can only appear in operation $[8,26]$.

In many situations, the decision information is expressed in the form of uncertain linguistic variables [24-28] because of time pressure, lack of knowledge or data, and their limited expertise related to the problem domain. Let $\widetilde{s}=\left[s_{\alpha}, s_{\beta}\right]$, where $s_{\alpha}, s_{\beta} \in \bar{S}, s_{\alpha}$, and $s_{\beta}$ are the lower and the upper limits, respectively, then we call $\widetilde{s}$ the uncertain linguistic variable $[26,27]$. Let $\widetilde{S}$ be the set of all the uncertain linguistic variables.

For any three uncertain linguistic variables $\widetilde{s}=\left[s_{\alpha}, s_{\beta}\right]$, $\widetilde{s}_{1}=\left[s_{\alpha_{1}}, s_{\beta_{1}}\right], \widetilde{s}_{2}=\left[s_{\alpha_{2}}, s_{\beta_{2}}\right]$, the following two operational laws are valid:

(1) $\widetilde{s}_{1} \oplus \widetilde{s}_{2}=\left[s_{\alpha_{1}}, s_{\beta_{1}}\right] \oplus\left[s_{\alpha_{2}}, s_{\beta_{2}}\right]=\left[s_{\alpha_{1}} \oplus s_{\alpha_{2}}, s_{\beta_{1}} \oplus s_{\beta_{2}}\right]=$ $\left[s_{\alpha_{1}+\alpha_{2}}, s_{\beta_{1}+\beta_{2}}\right]$

(2) $\lambda \widetilde{s}=\lambda\left[s_{\alpha}, s_{\beta}\right]=\left[\lambda s_{\alpha}, \lambda s_{\beta}\right]=\left[s_{\lambda \alpha}, s_{\lambda \beta}\right]$, where $\lambda \epsilon$ $[0,1]$.

$\mathrm{Xu}$ [9] defined an uncertain linguistic distance between $\widetilde{s}_{1}$ and $\widetilde{s}_{2}$ as follows.

Definition 3. Let $\widetilde{s}_{1}=\left[s_{\alpha_{1}}, s_{\beta_{1}}\right], \widetilde{s}_{2}=\left[s_{\alpha_{2}}, s_{\beta_{2}}\right]$ be two uncertain linguistic labels, such that

$$
d\left(\widetilde{s}_{1}, \widetilde{s}_{2}\right)=\frac{1}{2}\left(\left|\alpha_{1}-\alpha_{2}\right|+\left|\beta_{1}-\beta_{2}\right|\right)
$$

is called an uncertain linguistic distance (ULD) between $\widetilde{s}_{1}$ and $\widetilde{s}_{2}$.
Based on the above information, now we can define the following uncertain linguistic weighted distance.

Definition 4. Let $A=\left(\widetilde{s}_{1}, \widetilde{s}_{2}, \ldots, \widetilde{s}_{n}\right)$ and $B=\left(\widetilde{s}_{1}, \widetilde{s}_{2}, \ldots, \widetilde{s}_{n}^{\prime}\right)$ be two collections of uncertain linguistic labels, and let $d\left(\widetilde{s}_{j}, \widetilde{s}_{j}\right)$ be the distance between $\widetilde{s}_{j}=\left[s_{\alpha_{j}}, s_{\beta_{j}}\right]$ and let $\vec{s}_{j}^{\prime}=\left[s_{\alpha_{j}}^{\prime}, s_{\beta_{j}}^{\prime}\right]$, then

$$
\operatorname{ULWHD}(A, B)=\sum_{j=1}^{n} w_{j} d\left(\tilde{s}_{j}, \tilde{s}_{j}^{\prime}\right)
$$

is called an uncertain linguistic weighted Hamming distance (ULWHD) between $A$ and $B$, where $w=\left(w_{1}, w_{2}, \ldots, w_{n}\right)$ is the weighting vector associated with the $d\left(\widetilde{s}_{j}, \widetilde{s}_{j}\right)$, such that $w_{j} \in[0,1]$ and $\sum_{j=1}^{n} w_{j}=1$.

Definition 5. Let $A=\left(\widetilde{s}_{1}, \widetilde{s}_{2}, \ldots, \widetilde{s}_{n}\right)$ and $B=\left(\widetilde{s}_{1}, \widetilde{s}_{2}, \ldots, \widetilde{s}_{n}^{\prime}\right)$ be two collections of uncertain linguistic labels, and let $d\left(\widetilde{s}_{j}, \widetilde{s}_{j}\right)$ be the distance between $\tilde{s}_{j}=\left[s_{\alpha_{j}}, s_{\beta_{j}}\right]$ and $\widetilde{s}_{j}^{\prime}=\left[s_{\alpha_{j}}^{\prime}, s_{\beta_{j}}^{\prime}\right]$, then

$$
\operatorname{ULWED}(A, B)=\sqrt{\sum_{j=1}^{n} w_{j}\left(d\left(\widetilde{s}_{j}, \widetilde{s}_{j}\right)\right)^{2}}
$$

is called an uncertain linguistic weighted Euclidean distance (ULWED) between $A$ and $B$, where $w=\left(w_{1}, w_{2}, \ldots, w_{n}\right)$ is the weighting vector associated with the $d\left(\widetilde{s}_{j}, \widetilde{s}_{j}^{\prime}\right)$, such that $w_{j} \in[0,1]$ and $\sum_{j=1}^{n} w_{j}=1$. form:

Now we generalized both (10) and (11) to the following

$$
\operatorname{ULWD}(A, B)=\left(\sum_{j=1}^{n} w_{j}\left(d\left(\widetilde{s}_{j}, \vec{s}_{j}\right)\right)^{\lambda}\right)^{1 / \lambda}
$$

which is called an uncertain linguistic weighted distance (ULWD) between $A$ and $B$. Specially, if $\lambda=1$, then the ULWD measure is reduced to the ULWHD measure (10). If $\lambda=2$, then the ULWD measure is reduced to the ULWED measure (11).

Example 6. Let $A=\left(\widetilde{s}_{1}, \widetilde{s}_{2}, \widetilde{s}_{3}, \widetilde{s}_{4}\right)=\left(\left[s_{0}, s_{1}\right],\left[s_{-1}, s_{1}\right],\left[s_{1}, s_{2}\right]\right.$, $\left.\left[s_{0}, s_{3}\right]\right), B=\left(\vec{s}_{1}, \vec{s}_{2}, \vec{s}_{3}, \vec{s}_{4}^{\prime}\right)=\left(\left[s_{-1}, s_{0}\right],\left[s_{1}, s_{2}\right],\left[s_{-1}, s_{2}\right],\left[s_{1}\right.\right.$, $\left.s_{3}\right]$ ) be two collections of uncertain linguistic labels, then

$$
d\left(\widetilde{s}_{1}, \widetilde{s}_{1}^{\prime}\right)=\frac{1}{2}(|0-(-1)|+|1-0|)=1 .
$$

Similarly, we can get

$$
d\left(\widetilde{s}_{2}, \widetilde{s}_{2}^{\prime}\right)=1.5, \quad d\left(\widetilde{s}_{3}, \widetilde{s}_{3}^{\prime}\right)=1, \quad d\left(\widetilde{s}_{4}, \widetilde{s}_{4}^{\prime}\right)=0.5 .
$$

Suppose that $w=(0.2,0.3,0.3,0.2)$, and without loss of generality, let $\lambda=2$, then by (12), we can get the weighted distance between $A$ and $B$ as follows

$\operatorname{ULWD}(A, B)$

$$
\begin{aligned}
& =\left(0.2 \times 1^{2}+0.3 \times 1.5^{2}+0.3 \times 1^{2}+0.2 \times 0.5^{2}\right)^{1 / 2} \\
& =1.225
\end{aligned}
$$


The fundamental aspect of the ULWD measure is that it only takes the importance of the given individual distances into consideration, and then aggregates these difference elements together with their weights under the parameter $\lambda$.

\section{Uncertain Linguistic OWD (ULOWD) Measure}

Based on the (7) and (12), we define an uncertain linguistic ordered weighted distance measure as follows.

Definition 7. Let $A=\left(\widetilde{s}_{1}, \widetilde{s}_{2}, \ldots, \widetilde{s}_{n}\right)$ and $B=\left(\vec{s}_{1}^{\prime}, \widetilde{s}_{2}^{\prime}, \ldots, \vec{s}_{n}^{\prime}\right)$ be two collections of uncertain linguistic labels, and $d\left(\widetilde{s}_{j}, \widetilde{s}_{j}^{\prime}\right)$ be the distance between $\widetilde{s}_{j}=\left[s_{\alpha_{j}}, s_{\beta_{j}}\right]$ and $\widetilde{s}_{j}=\left[\widetilde{s}_{\alpha_{j}}, \widetilde{s}_{\beta_{j}}\right]$, then

$$
\operatorname{ULOWD}(A, B)=\left(\sum_{j=1}^{n} w_{j}\left(d\left(\widetilde{s}_{\sigma(j)}, \vec{s}_{\sigma(j)}\right)\right)^{\lambda}\right)^{1 / \lambda}
$$

is called an uncertain linguistic ordered weighted distance (ULOWD) between $A$ and $B$, where $(\sigma(1), \sigma(2), \ldots, \sigma(n))$ is any permutation of $(1,2, \ldots, n)$, such that

$$
d\left(\widetilde{s}_{\sigma(j-1)}, \widetilde{s}_{\sigma(j-1)}\right) \geq d\left(\widetilde{s}_{\sigma(j)}, \vec{s}_{\sigma(j)}\right), \quad j=1,2, \ldots, n
$$

$w=\left(w_{1}, w_{2}, \ldots, w_{n}\right)$ is the weighting vector associated with the ULOWD measure such that $w_{j} \in[0,1]$ and $\sum_{j=1}^{n} w_{j}=$ 1. Specially, if $\lambda=1$, then the ULOWD measure is called an uncertain linguistic ordered weighted Hamming distance (ULOWHD) measure:

$$
\operatorname{ULOWHD}(A, B)=\sum_{j=1}^{n} w_{j} d\left(\widetilde{s}_{\sigma(j)}, \widetilde{s}_{\sigma(j)}^{\prime}\right) .
$$

If $\lambda=2$, then the ULOWD measure is reduced to the uncertain linguistic ordered weighted Euclidean distance (ULOWED) measure:

$$
\operatorname{ULOWED}(A, B)=\left(\sum_{j=1}^{n} w_{j}\left(d\left(\widetilde{s}_{\sigma(j)}, \widetilde{s}_{\sigma(j)}\right)\right)^{2}\right)^{1 / 2} .
$$

Example 8. Let $A=\left(\widetilde{s}_{1}, \widetilde{s}_{2}, \widetilde{s}_{3}, \widetilde{s}_{4}\right)=\left(\left[s_{0}, s_{1}\right],\left[s_{-1}, s_{1}\right],\left[s_{1}, s_{2}\right]\right.$, $\left.\left[s_{0}, s_{3}\right]\right), B=\left(\vec{s}_{1}, \vec{s}_{2}, \vec{s}_{3}, \vec{s}_{4}^{\prime}\right)=\left(\left[s_{-1}, s_{0}\right],\left[s_{1}, s_{2}\right],\left[s_{-1}, s_{2}\right],\left[s_{1}\right.\right.$, $\left.s_{3}\right]$ ) be two collections of uncertain linguistic labels, then

$$
d\left(\widetilde{s}_{1}, \widetilde{s}_{1}^{\prime}\right)=\frac{1}{2}(|0-(-1)|+|1-0|)=1 .
$$

Similarly, we can get

$$
d\left(\widetilde{s}_{2}, \widetilde{s}_{2}\right)=1.5, \quad d\left(\widetilde{s}_{3}, \widetilde{s}_{3}^{\prime}\right)=1, \quad d\left(\widetilde{s}_{4}, \widetilde{s}_{4}^{\prime}\right)=0.5 .
$$

Reordering the above individual distances in descending order, then we get

$$
\begin{gathered}
d\left(\widetilde{s}_{\sigma(1)}, \vec{s}_{\sigma(1)}^{\prime}\right)=1.5, \quad d\left(\widetilde{s}_{\sigma(2)}, \vec{s}_{\sigma(2)}^{\prime}\right)=d\left(\widetilde{s}_{\sigma(3)}, \vec{s}_{\sigma(3)}^{\prime}\right)=1, \\
d\left(\widetilde{s}_{\sigma(4)}, \widetilde{s}_{\sigma(4)}^{\prime}\right)=0.5 .
\end{gathered}
$$

Suppose that $w=(0.2,0.3,0.3,0.2)$, and without loss of generality, let $\lambda=2$, then by (16), we can get the ordered weighted distance between $A$ and $B$ as follows

\section{$\operatorname{ULOWD}(A, B)$}

$$
\begin{aligned}
& =\left(0.2 \times 1.5^{2}+0.3 \times 1^{2}+0.3 \times 1^{2}+0.2 \times 0.5^{2}\right)^{1 / 2} \\
& =1.1
\end{aligned}
$$

From the above definitions, we know that the ULWD measure takes the importance of given individual distances into consideration, while the ULOWD measure only emphasizes the importance of the ordered position of the given individual distances, it weights the ordered position of the given individual distances instead of weighting arguments themselves. Therefore, weights represent different aspects in both the ULWD and ULOWD measures. However, both the ULWD and ULOWD operators consider only one of them. To solve this drawback, in the following, we will propose an uncertain linguistic hybrid weighted distance (ULHWD) measure.

\section{Uncertain Linguistic Hybrid Weighted Distance (ULHWD) Measure}

Definition 9. Let $A=\left(\widetilde{s}_{1}, \widetilde{s}_{2}, \ldots, \widetilde{s}_{n}\right)$ and $B=\left(\widetilde{s}_{1}, \widetilde{s}_{2}, \ldots, \widetilde{s}_{n}^{\prime}\right)$ be two collections of uncertain linguistic labels, and let $d\left(\widetilde{s}_{j}, \widetilde{s}_{j}\right)$ be the distance between $\tilde{s}_{j}=\left[s_{\alpha_{j}}, s_{\beta_{j}}\right]$ and $\vec{s}_{j}=\left[\vec{s}_{\alpha_{j}}, \vec{s}_{\beta_{j}}\right]$, then

$$
\operatorname{ULHWD}(A, B)=\left(\sum_{j=1}^{n} w_{j} \dot{d}\left(a_{\sigma(j)}, a_{\sigma(j)}\right)\right)^{1 / \lambda}
$$

is called an uncertain linguistic hybrid weighted distance (ULHWD) between $A$ and $B$, where $\dot{d}\left(\widetilde{s}_{\sigma(j)}, \vec{s}_{\sigma(j)}\right)$ represents the $j$ th largest of the weighted distance $\dot{d}\left(\widetilde{s}_{j}, \widetilde{s}_{j}\right)$ (here $\left.\dot{d}\left(\widetilde{s}_{j}, \widetilde{s}_{j}^{\prime}\right)=n \omega_{j}\left(d\left(\widetilde{s}_{j}, \vec{s}_{j}\right)\right)^{\lambda}, j=1,2, \ldots, n\right), w=\left(w_{1}, w_{2}, \ldots\right.$, $w_{n}$ ) is the weighting vector associated with the ULHWD measure, $\omega=\left(\omega_{1}, \omega_{2}, \ldots, \omega_{n}\right)^{T}$ is the weighting vector of the $d\left(\widetilde{s}_{j}, \widetilde{s}_{j}\right)$, with $\omega_{i} \in[0,1]$ and the the sum of the weights is $1 . n$ is the balancing coefficient, which plays a role of balance (in such a case, if the vector $\omega=\left(\omega_{1}, \omega_{2}, \ldots, \omega_{n}\right)$ approaches $(1 / n, 1 / n, \ldots, 1 / n)$, then $\left(n \omega_{1}\left|\widetilde{s}_{1}-\widetilde{s}_{1}\right|^{\lambda}, n \omega_{2}\left|\widetilde{s}_{2}-\widetilde{s}_{2}^{\lambda}\right|^{\lambda}, \ldots, n \omega_{n}\left|\widetilde{s}_{n}-\widetilde{s}_{n}^{\lambda}\right|^{\lambda}\right) \quad$ approaches $\left(\left|\widetilde{s}_{1}-\widetilde{s}_{1}\right|^{\lambda},\left|\widetilde{s}_{2}-\widetilde{s}_{2}\right|^{\lambda}, \ldots,\left|\widetilde{s}_{n}-\widetilde{s}_{n}^{\prime}\right|^{\lambda}\right)$.

Example 10. Let $A=\left(\widetilde{s}_{1}, \widetilde{s}_{2}, \widetilde{s}_{3}, \widetilde{s}_{4}, \widetilde{s}_{5}\right)=\left(\left[s_{1}, s_{3}\right],\left[s_{-1}, s_{2}\right]\right.$, $\left.\left[s_{0}, s_{2}\right],\left[s_{-2}, s_{0}\right],\left[s_{-1}, s_{3}\right]\right), B=\left(\widetilde{s}_{1}, \widetilde{s}_{2}, \widetilde{s}_{3}, \widetilde{s}_{4}, \widetilde{s}_{5}\right)=\left(\left[s_{3}, s_{4}\right],\left[s_{0}\right.\right.$, $\left.\left.s_{1}\right],\left[s_{-2}, s_{2}\right],\left[s_{-1}, s_{2}\right],\left[s_{0}, s_{3}\right]\right)$ be two collections of uncertain linguistic labels, then

$$
d\left(\widetilde{s}_{1}, \widetilde{s}_{1}^{\prime}\right)=\frac{1}{2}(|1-3|+|3-4|)=1.5
$$


Similarly, we can get

$$
\begin{aligned}
& d\left(\widetilde{s}_{2}, \widetilde{s}_{2}^{\prime}\right)=1, \quad d\left(\widetilde{s}_{3}, \widetilde{s}_{3}^{\prime}\right)=1, \\
& d\left(\widetilde{s}_{4}, \widetilde{s}_{4}^{\prime}\right)=1.5, \quad d\left(\widetilde{s}_{5}, \widetilde{s}_{5}^{\prime}\right)=0.5 .
\end{aligned}
$$

Suppose that $\omega=(0.10,0.15,0.25,0.30,0.20)$, and without loss of generality, let $\lambda=2$, then we can get

$$
\dot{d}\left(s_{1}, s_{1}^{\prime}\right)=5 \times 0.10 \times 1.5^{2}=1.125 .
$$

Similarly, we can have

$$
\begin{array}{ll}
\dot{d}\left(s_{2}, s_{2}^{\prime}\right)=0.75, & \dot{d}\left(s_{3}, s_{3}^{\prime}\right)=1.25, \\
\dot{d}\left(s_{4}, s_{4}^{\prime}\right)=3.375, & \dot{d}\left(s_{5}, s_{5}^{\prime}\right)=0.25 .
\end{array}
$$

Reordering the above weighted distances in descending order, then we get

$$
\begin{gathered}
\dot{d}\left(\widetilde{s}_{\sigma(1)}, \widetilde{s}_{\sigma(1)}^{\prime}\right)=3.375, \quad \dot{d}\left(\widetilde{s}_{\sigma(2)}, \vec{s}_{\sigma(2)}^{\prime}\right)=1.25, \\
\dot{d}\left(\widetilde{s}_{\sigma(3)}, \widetilde{s}_{\sigma(3)}\right)=1.125, \quad \dot{d}\left(\widetilde{s}_{\sigma(4)}, \vec{s}_{\sigma(4)}^{\prime}\right)=0.75, \\
\dot{d}\left(\widetilde{s}_{\sigma(5)}, \widetilde{s}_{\sigma(5)}^{\prime}\right)=0.25 .
\end{gathered}
$$

Let the weighting vector associating with the ULHWD measure be $w=(0.11,0.24,0.30,0.24,0.11)$, which is derived by the normal distribution based method [37], then by (24), we can get the hybrid weighted distance between $A$ and $B$ :

$\operatorname{ULHWD}(A, B)$

$$
\begin{gathered}
=(0.11 \times 3.375+0.24 \times 1.25+0.30 \times 1.125 \\
+0.24 \times 0.75+0.11 \times 0.25)^{1 / 2}=1.1028 .
\end{gathered}
$$

Theorem 11. The ULWD measure is a special case of the ULHWD measure.

Proof. Let $w=(1 / n, 1 / n, \ldots, 1 / n)$, then

$$
\begin{aligned}
\operatorname{ULHWD}(A, B) & =\left(\sum_{j=1}^{n} w_{j} \dot{d}\left(\widetilde{s}_{\sigma(j)}, \vec{s}_{\sigma(j)}^{\prime}\right)\right)^{1 / \lambda} \\
& =\left(\frac{1}{n} \sum_{j=1}^{n} \dot{d}\left(\widetilde{s}_{j}, \widetilde{s}_{j}\right)\right)^{1 / \lambda} \\
& =\left(\frac{1}{n} \sum_{j=1}^{n} n \omega_{j}\left(d\left(\widetilde{s}_{j}, \widetilde{s}_{j}^{\prime}\right)\right)^{\lambda}\right)^{1 / \lambda} \\
& =\left(\sum_{j=1}^{n} \omega_{j}\left(d\left(\widetilde{s}_{j}, \widetilde{s}_{j}^{\prime}\right)\right)^{\lambda}\right)^{1 / \lambda} \\
& =\operatorname{ULWD}(A, B)
\end{aligned}
$$

which completes the proof of Theorem 11.
Theorem 12. The ULOWD measure is a special case of the ULHWD measure.

Proof. Let $\omega=(1 / n, 1 / n, \ldots, 1 / n)$, then

$$
\dot{d}\left(\widetilde{s}_{\sigma(j)}, \widetilde{s}_{\sigma(j)}^{\prime}\right)=n \omega_{j}\left(d\left(\widetilde{s}_{\sigma(j)}, \widetilde{s}_{\sigma(j)}^{\prime}\right)\right)^{\lambda}=\left(d\left(\widetilde{s}_{\sigma(j)}, \widetilde{s}_{\sigma(j)}^{\prime}\right)\right)^{\lambda}
$$

which completes the proof of Theorem 12.

From Definition 9 and the above theorems, we know that

(1) the ULHWD measure first weights the given individual distances, and then reorders the weighted individual distances in descending order and weights these ordered individual distances by the ULHWD weights and finally aggregates these individual distances into a collective one under the parameter $\lambda$;

(2) the ULHWD measure generalizes both the ULWD and ULOWD measure and reflects the importance degrees of both the given individual distances and their ordered positions.

In addition, a prominent characteristic of the ULHWD measure is that it can relieve (or intensify) the influence of unduly large or unduly small difference elements on the aggregation results by assigning them low (or high) weights.

\section{An Approach to Group Decision Making Based on the ULHWD Measure}

For a group decision making problem, let $X=\left\{x_{1}, x_{2}, \ldots, x_{n}\right\}$ be a finite set of alternatives, let and $E=\left\{e_{1}, e_{2}, \ldots, e_{m}\right\}$ be the set of decision makers (whose weight vector is $v=$ $\left.\left(v_{1}, v_{2}, \ldots, v_{m}\right), v_{k} \geq 0, \sum_{k=1}^{m} v_{k}=1\right)$. The decision makers $e_{k}(k=1,2, \ldots, m)$ provide their preferences with uncertain linguistic labels $a_{k j}(k=1,2, \ldots, m ; j=1,2, \ldots, n)$ over all the alternatives $x_{j}(j=1,2, \ldots, n)$ in respect to a criterion. For convenience, we denote the preference vectors of all the decision makers $e_{k}(k=1,2, \ldots, m)$ as

$$
A_{k}=\left(a_{k 1}, a_{k 2}, \ldots, a_{k n}\right), \quad k=1,2, \ldots, m .
$$

Based on the above decision information, we can utilize the ULHWD measure to develop an approach to reaching consensus of group opinions, which can be summarized as follows [18].

Step 1. Calculate the collective preference vector $A_{0}=$ $\left(a_{01}, a_{02}, \ldots, a_{0 n}\right)$ by using the uncertain linguistic weighted averaging (ULWA) operator [26], where

$$
a_{0 j}=v_{1} a_{1 j} \oplus v_{2} a_{2 j} \oplus \cdots v_{m} a_{m j}, \quad j=1,2, \ldots n .
$$

Step 2. By (24), we calculate

$$
\operatorname{ULHWD}\left(A_{k}, A_{0}\right)=\left(\sum_{j=1}^{n} w_{k j} \dot{d}\left(a_{\sigma(k j)}, a_{\sigma(0 j)}\right)\right)^{1 / \lambda}
$$


TABLE 1: The decision makers' preferences.

\begin{tabular}{cccccccc}
\hline & $x_{1}$ & $x_{2}$ & $x_{3}$ & $x_{4}$ & $x_{5}$ & $x_{6}$ & $x_{7}$ \\
\hline$e_{1}$ & {$\left[s_{1}, s_{2}\right]$} & {$\left[s_{0}, s_{2}\right]$} & {$\left[s_{1}, s_{2}\right]$} & {$\left[s_{2}, s_{3}\right]$} & {$\left[s_{2}, s_{3}\right]$} & {$\left[s_{0}, s_{2}\right]$} & {$\left[s_{2}, s_{3}\right]$} \\
$e_{2}$ & {$\left[s_{0}, s_{2}\right]$} & {$\left[s_{1}, s_{3}\right]$} & {$\left[s_{2}, s_{3}\right]$} & {$\left[s_{0}, s_{1}\right]$} & {$\left[s_{1}, s_{2}\right]$} & {$\left[s_{1}, s_{2}\right]$} & {$\left[s_{1}, s_{3}\right]$} \\
$e_{3}$ & {$\left[s_{1}, s_{2}\right]$} & {$\left[s_{0}, s_{2}\right]$} & {$\left[s_{1}, s_{3}\right]$} & {$\left[s_{1}, s_{2}\right]$} & {$\left[s_{2}, s_{3}\right]$} & {$\left[s_{1}, s_{2}\right]$} & {$\left[s_{0}, s_{2}\right]$} \\
$e_{4}$ & {$\left[s_{1}, s_{2}\right]$} & {$\left[s_{2}, s_{3}\right]$} & {$\left[s_{0}, s_{2}\right]$} & {$\left[s_{0}, s_{1}\right]$} & {$\left[s_{2}, s_{4}\right]$} & {$\left[s_{1}, s_{2}\right]$} & {$\left[s_{2}, s_{3}\right]$} \\
$e_{5}$ & {$\left[s_{0}, s_{1}\right]$} & {$\left[s_{1}, s_{2}\right]$} & {$\left[s_{1}, s_{2}\right]$} & {$\left[s_{0}, s_{1}\right]$} & {$\left[s_{0}, s_{3}\right]$} & {$\left[s_{2}, s_{3}\right]$} & {$\left[s_{1}, s_{2}\right]$} \\
\hline
\end{tabular}

which is the distance between the preference vectors $A_{k}$ and $A_{0}$, where $\dot{d}\left(a_{\sigma(k j)}, a_{\sigma(0 j)}\right)$ is the $j$ th largest of the $\dot{d}\left(a_{k j}, a_{0 j}\right)$ (here $\left.\dot{d}\left(a_{k j}, a_{0 j}\right)=n \omega_{j} d\left(a_{k j}, a_{0 j}\right)\right), j=1,2, \ldots, n$, the weighting vector associating with the ULHWD measure can be derived by using some determining methods like the normal distribution based method, see [37] for more details.

Step 3. If all $\operatorname{ULHWD}\left(A_{k}, A_{0}\right) \leq \eta(k=1,2, \ldots, m)$, then the group is of acceptable consensus, where $\eta$ is the threshold value of acceptable consensus, which can be determined by the group in practical applications. Otherwise, if there exists some $k_{0}$, such that $\operatorname{ULHWD}\left(A_{k_{0}}, A_{0}\right)>\eta$, then we will return $A_{k_{0}}$ (together with $A_{0}$ as a reference) to the decision maker $e_{k}$ for revaluation and repeat this procedure until $\operatorname{ULHWD}\left(A_{k_{0}}, A_{0}\right) \leq \eta$ or the process will stop as the repetition times reach the maximum number predefined by the group.

\section{Illustrative Example}

A group decision problem of evaluating university faculty for tenure and promotion (adapted from [13]) is used to illustrate the developed approach. One main criterion used is "teaching." There are five decision makers $e_{k}(k=1,2, \ldots, 5)$ (whose weighting vector is $v=(0.20,0.15,0.25,0.30,0.10)$ ) and there are seven faculty candidates (alternatives) $x_{j}(j=$ $1,2, \ldots, 7)$. By using linguistic label set (8), each decision maker $e_{k}$ provides his/her preferences $a_{k j} \in \widetilde{S}(j=1,2, \ldots, 7)$ over all the faculty candidates $x_{j}(j=1,2, \ldots, 7)$, shown in Table 1.

For convenience, we denote the preferences of all the decision makers $e_{k}(k=1,2, \ldots, 5)$ in the vector forms:

$$
\begin{aligned}
A_{1}= & \left(a_{11}, a_{12}, \ldots, a_{17}\right) \\
= & \left(\left[s_{1}, s_{2}\right],\left[s_{0}, s_{2}\right],\left[s_{1}, s_{2}\right],\left[s_{2}, s_{3}\right],\right. \\
& {\left.\left[s_{2}, s_{3}\right],\left[s_{0}, s_{2}\right],\left[s_{2}, s_{3}\right]\right), } \\
A_{2}= & \left(a_{21}, a_{22}, \ldots, a_{27}\right) \\
= & \left(\left[s_{0}, s_{2}\right],\left[s_{1}, s_{3}\right],\left[s_{2}, s_{3}\right],\left[s_{0}, s_{1}\right],\right. \\
& {\left.\left[s_{1}, s_{2}\right],\left[s_{1}, s_{2}\right],\left[s_{1}, s_{3}\right]\right), } \\
A_{3}= & \left(a_{31}, a_{32}, \ldots, a_{37}\right) \\
= & \left(\left[s_{1}, s_{2}\right],\left[s_{0}, s_{2}\right],\left[s_{1}, s_{3}\right],\left[s_{1}, s_{2}\right],\right. \\
& {\left.\left[s_{2}, s_{3}\right],\left[s_{1}, s_{2}\right],\left[s_{0}, s_{2}\right]\right), }
\end{aligned}
$$

$$
\begin{aligned}
A_{4}= & \left(a_{41}, a_{42}, \ldots, a_{47}\right) \\
= & \left(\left[s_{1}, s_{2}\right],\left[s_{2}, s_{3}\right],\left[s_{0}, s_{2}\right],\left[s_{0}, s_{1}\right],\right. \\
& {\left.\left[s_{2}, s_{4}\right],\left[s_{1}, s_{2}\right],\left[s_{2}, s_{3}\right]\right), } \\
A_{5}= & \left(a_{51}, a_{52}, \ldots, a_{57}\right) \\
= & \left(\left[s_{0}, s_{1}\right],\left[s_{1}, s_{2}\right],\left[s_{1}, s_{2}\right],\left[s_{0}, s_{1}\right],\right. \\
& {\left.\left[s_{0}, s_{3}\right],\left[s_{2}, s_{3}\right],\left[s_{1}, s_{2}\right]\right) . }
\end{aligned}
$$

Then, we can calculate the collective preference vector by using (34):

$$
\begin{aligned}
A_{0}= & \left(a_{01}, a_{02}, \ldots, a_{07}\right) \\
= & \left(\left[s_{0.75}, s_{1.9}\right],\left[s_{0.85}, s_{2.45}\right],\left[s_{0.85}, s_{2.4}\right],\right. \\
& \left.\quad\left[s_{0.65}, s_{1.65}\right],\left[s_{1.65}, s_{3.75}\right],\left[s_{0.90}, s_{2.1}\right],\left[s_{1.25}, s_{2.65}\right]\right) .
\end{aligned}
$$

Then, utilize (9) to calculate the distance $d\left(a_{k j}, a_{0 j}\right)$ of the corresponding collective preference value $a_{0 j}$ and the corresponding preference value $a_{k j}$ provided by the decision maker $e_{k}$ :

$$
\begin{aligned}
& d\left(a_{11}, a_{01}\right)=0.175, \quad d\left(a_{12}, a_{02}\right)=0.75, \\
& d\left(a_{13}, a_{03}\right)=0.275 \\
& d\left(a_{14}, a_{04}\right)=1.35, \quad d\left(a_{15}, a_{05}\right)=0.55 \text {, } \\
& d\left(a_{16}, a_{06}\right)=0.50 \\
& d\left(a_{17}, a_{07}\right)=0.55, \quad d\left(a_{21}, a_{01}\right)=0.425, \\
& d\left(a_{22}, a_{02}\right)=0.35 \\
& d\left(a_{23}, a_{03}\right)=0.875, \quad d\left(a_{24}, a_{04}\right)=0.65 \text {, } \\
& d\left(a_{25}, a_{05}\right)=1.20 \\
& d\left(a_{26}, a_{06}\right)=0.10, \quad d\left(a_{27}, a_{07}\right)=0.30, \\
& d\left(a_{31}, a_{01}\right)=0.175 \\
& d\left(a_{32}, a_{02}\right)=0.75, \quad d\left(a_{33}, a_{03}\right)=0.325 \text {, } \\
& d\left(a_{34}, a_{04}\right)=0.35 \\
& d\left(a_{35}, a_{05}\right)=0.55, \quad d\left(a_{36}, a_{06}\right)=0.10, \\
& d\left(a_{37}, a_{07}\right)=0.95 \\
& d\left(a_{41}, a_{01}\right)=0.175, \quad d\left(a_{42}, a_{02}\right)=0.85, \\
& d\left(a_{43}, a_{03}\right)=0.625 \\
& d\left(a_{44}, a_{04}\right)=0.65, \quad d\left(a_{45}, a_{05}\right)=0.30,
\end{aligned}
$$




$$
\begin{gathered}
d\left(a_{46}, a_{06}\right)=0.10 \\
d\left(a_{47}, a_{07}\right)=0.55, \quad d\left(a_{51}, a_{01}\right)=0.825, \\
d\left(a_{52}, a_{02}\right)=0.30 \\
d\left(a_{53}, a_{03}\right)=0.275, \quad d\left(a_{54}, a_{04}\right)=0.65, \\
d\left(a_{55}, a_{05}\right)=1.20 \\
d\left(a_{56}, a_{06}\right)=1.0, \quad d\left(a_{57}, a_{07}\right)=0.45 .
\end{gathered}
$$

Without loss of generality, let $\lambda=1$ and $\omega=(0.12,0.15$, $0.10,0.13,0.14,0.20,0.16)$, suppose that the weighting vector associating with the ULHWD measure is $w=(0.07,0.13$, $0.19,0.22,0.19,0.13,0.07)$, which is derived by using the normal distribution based method [37], then we calculate distance $\operatorname{ULHWD}\left(A_{k}, A_{0}\right)$ between the preference vectors $A_{k}$ and $A_{0}$ :

$$
\begin{array}{ll}
\operatorname{ULhWD}\left(A_{1}, A_{0}\right)=0.59, & \operatorname{ULhWD}\left(A_{2}, A_{0}\right)=0.48, \\
\operatorname{ULHWD}\left(A_{3}, A_{0}\right)=0.42, & \operatorname{ULhWD}\left(A_{4}, A_{0}\right)=0.44,
\end{array}
$$$$
\operatorname{ULHWD}\left(A_{5}, A_{0}\right)=0.66 \text {. }
$$

Let us suppose the threshold value of acceptable consensus is $\eta=0.60$, then $\operatorname{ULHWD}\left(A_{k}, A_{0}\right)<0.60(k=1,2,3,4)$, $\operatorname{ULHWD}\left(A_{5}, A_{0}\right)>0.60$, and thus, we need to return $A_{5}$ (together with $A_{0}$ as a reference) to the decision maker $e_{5}$ for revaluation. Suppose that the revaluated $A_{5}$ is

$$
\begin{aligned}
A_{5}= & \left(a_{51}, a_{52}, \ldots, a_{57}\right) \\
= & \left(\left[s_{0}, s_{1}\right],\left[s_{1}, s_{2}\right],\left[s_{1}, s_{2}\right],\left[s_{0}, s_{1}\right],\right. \\
& {\left.\left[s_{0}, s_{2}\right],\left[s_{1}, s_{2}\right],\left[s_{1}, s_{2}\right]\right) . }
\end{aligned}
$$

Then, we can calculate the collective preference vector by using (34):

$$
\begin{aligned}
A_{0}= & \left(a_{01}, a_{02}, \ldots, a_{07}\right) \\
= & \left(\left[s_{0.75}, s_{1.9}\right],\left[s_{0.85}, s_{2.45}\right],\left[s_{0.85}, s_{2.4}\right],\right. \\
& {\left.\left[s_{0.65}, s_{1.65}\right],\left[s_{1.65}, s_{3.05}\right],\left[s_{0.80}, s_{2.0}\right],\left[s_{1.25}, s_{2.65}\right]\right) . }
\end{aligned}
$$

Respectively, then by (9) and (24) (let $\lambda=1$ ), we get

$$
\begin{aligned}
& \operatorname{ULhWD}\left(A_{1}, A_{0}\right)=0.50, \quad \operatorname{ULhWD}\left(A_{2}, A_{0}\right)=0.45, \\
& \operatorname{ULHWD}\left(A_{3}, A_{0}\right)=0.35, \quad \operatorname{ULHWD}\left(A_{4}, A_{0}\right)=0.49,
\end{aligned}
$$

$$
\operatorname{ULHWD}\left(A_{5}, A_{0}\right)=0.51 \text {. }
$$

Thus, all the distances $\operatorname{ULHWD}\left(A_{k}, A_{0}\right)(k=1,2,3,4,5)$ are less than 0.60 , which indicates that the group reaches consensus.

\section{Conclusions}

In this paper,we have suggested several extensions of the OWD measure when dealing with uncertain situations. The increasing complexity of the socioeconomic environment makes it more suitable for a decision maker to express his/her preferences over alternatives with uncertain linguistic information instead of exact numerical values. We have developed some uncertain linguistic aggregation distance measures. such as the uncertain linguistic weighted distance measure (ULWD), the uncertain linguistic ordered weighted distance measure (ULOWD), and the uncertain linguistic hybrid weighted distance measure (ULHWD). These developed distance measures are very suitable to deal with the situation where the input data is represented in uncertain linguistic information. We have analyzed that the ULHWD measure generalizes both the ULWD and ULOWD measure, and reflects the importance degrees of both the given difference element and their ordered positions. Finally, based on the ULHWD measure, we have proposed a consensus reaching process for group decision making with uncertain linguistic preference information.

\section{Acknowledgments}

The work was supported by the Projects in Science and Technique of Ningbo Municipal (no. 2012B82003), the MOE Project of Key Research Institute of Humanities and Social Sciences in Universities (no. 13JJD910002), and Humanities and Social Science Key Research Base (Statistics) of Zhejiang College.

\section{References}

[1] J. Gil-Aluja, Elements for a Theory of Decision in Uncertainty, Kluwer Academic Publishers, Dordrecht, The Netherlands, 1999.

[2] B. B. Chaudhuri and A. Rosenfeld, "A modified Hausdorff distance between fuzzy sets," Information Sciences, vol. 118, no. 1-4, pp. 159-171, 1999.

[3] J. M. Merigó and M. Casanovas, "Induced aggregation operators in the Euclidean distance and its application in financial decision making," Expert Systems with Applications, vol. 38, no. 6, pp. 7603-7608, 2011.

[4] E. Szmidt and J. Kacprzyk, "Distances between intuitionistic fuzzy sets," Fuzzy Sets and Systems, vol. 114, no. 3, pp. 505-518, 2000.

[5] N. B. Karayiannis, "Soft learning vector quantization and clustering algorithms based on ordered weighted aggregation operators," IEEE Transactions on Neural Networks, vol. 11, no. 5, pp. 1093-1105, 2000.

[6] A. Kaufmann, Introduction to the Theory of Fuzzy Subsets, Academic Press, New York, NY, USA, 1975.

[7] M. Izadikhah, "Using the Hamming distance to extend TOPSIS in a fuzzy environment," Journal of Computational and Applied Mathematics, vol. 231, no. 1, pp. 200-207, 2009.

[8] Z. Xu, "Deviation measures of linguistic preference relations in group decision making," Omega, vol. 33, no. 3, pp. 249-254, 2005. 
[9] Z. Xu, "An approach to pure linguistic multiple attribute decision making under uncertainty, International Journal of Information Technology and Decision Making, vol. 4, no. 2, pp. 197-206, 2005.

[10] Z. Xu and M. Xia, "Distance and similarity measures for hesitant fuzzy sets," Information Sciences, vol. 181, no. 11, pp. 2128-2138, 2011.

[11] R. W. Hamming, "Error detecting and error correcting codes," The Bell System Technical Journal, vol. 29, pp. 147-160, 1950.

[12] R. R. Yager, "On ordered weighted averaging aggregation operators in multicriteria decisionmaking," IEEE Transactions on Systems, Man, and Cybernetics, vol. 18, no. 1, pp. 183-190, 1988.

[13] Z. Xu and J. Chen, "Ordered weighted distance measure," Journal of Systems Science and Systems Engineering, vol. 17, no. 4, pp. 432-445, 2008.

[14] R. R. Yager, "Norms induced from oWA operators," IEEE Transactions on Fuzzy Systems, vol. 18, no. 1, pp. 57-66, 2010.

[15] J. M. Merigó and A. M. Gil-Lafuente, "New decision-making techniques and their application in the selection of financial products," Information Sciences, vol. 180, no. 11, pp. 2085-2094, 2010.

[16] S. Z. Zeng and W. H. Su, "Intuitionistic fuzzy ordered weighted distance operator," Knowledge-Based Systems, vol. 24, no. 8, pp. 1224-1232, 2011.

[17] K. T. Atanassov, "Intuitionistic fuzzy sets," Fuzzy Sets and Systems, vol. 20, no. 1, pp. 87-96, 1986.

[18] S. Z. Zeng, "Some intuitionistic fuzzy weighted distance measures and their application to group decision making," Group Decision and Negotiation, vol. 22, no. 2, pp. 281-298, 2013.

[19] Z. S. Xu, "Fuzzy ordered distance measures," Fuzzy Optimization and Decision Making, vol. 11, no. 1, pp. 73-97, 2012.

[20] J. M. Merigó and M. Casanovas, "Induced and heavy aggregation operators with distance measures," Journal of Systems Engineering and Electronics, vol. 21, no. 3, pp. 431-439, 2010.

[21] J. M. Merigó and M. Casanovas, "Decision making with distance measures and induced aggregation operators," Computers \& Industrial Engineering, vol. 60, no. 1, pp. 66-76, 2011.

[22] J. M. Merigó and M. Casanovas, "Decision making with distance measures and linguistic aggregation operators," International Journal of Fuzzy Systems, vol. 12, no. 4, pp. 190-198, 2010.

[23] J. M. Merigó and M. Casanovas, "A new Minkowski distance based on induced aggregation operators," International Journal of Computational Intelligence Systems, vol. 4, no. 2, pp. 123-133, 2011.

[24] F. Herrera and E. Herrera-Viedma, "Choice functions and mechanisms for linguistic preference relations," European Journal of Operational Research, vol. 120, no. 1, pp. 144-161, 2000.

[25] G.-W. Wei, "Uncertain linguistic hybrid geometric mean operator and its application to group decision making under uncertain linguistic environment," International Journal of Uncertainty, Fuzziness and Knowledge-Based Systems, vol. 17, no. 2, pp. 251-267, 2009.

[26] Z. S. Xu, "Uncertain linguistic aggregation operators based approach to multiple attribute group decision making under uncertain linguistic environment," Information Sciences, vol. 168, no. 1-4, pp. 171-184, 2004.

[27] Z. Xu, "An approach based on the uncertain LOWG and induced uncertain LOWG operators to group decision making with uncertain multiplicative linguistic preference relations," Decision Support Systems, vol. 41, no. 2, pp. 488-499, 2006.
[28] Z. Xu, "An interactive approach to multiple attribute group decision making with multigranular uncertain linguistic information," Group Decision and Negotiation, vol. 18, no. 2, pp. 119145, 2009.

[29] B. S. Ahn, "Some remarks on the LSOWA approach for obtaining OWA operator weights," International Journal of Intelligent Systems, vol. 24, no. 12, pp. 1265-1279, 2009.

[30] H. Y. Chen and L. G. Zhou, "An approach to group decision making with interval fuzzy preference relations based on induced generalized continuous ordered weighted averaging operator," Expert Systems with Applications, vol. 38, no. 10, pp. 13432-13440, 2011.

[31] X. Liu, "A general model of parameterized OWA aggregation with given orness level," International Journal of Approximate Reasoning, vol. 48, no. 2, pp. 598-627, 2008.

[32] X. Liu and S. Han, "Orness and parameterized RIM quantifier aggregation with OWA operators: a summary," International Journal of Approximate Reasoning, vol. 48, no. 1, pp. 77-97, 2008.

[33] J. M. Merigó and M. Casanovas, "The uncertain induced quasiarithmetic OWA operator," International Journal of Intelligent Systems, vol. 26, no. 1, pp. 1-24, 2011.

[34] J. M. Merigó and A. M. Gil-Lafuente, “The induced generalized OWA operator," Information Sciences, vol. 179, no. 6, pp. 729741, 2009.

[35] G. W. Wei, "Some induced geometric aggregation operators with intuitionistic fuzzy information and their application to group decision making," Applied Soft Computing Journal, vol. 10, no. 2, pp. 423-431, 2010.

[36] G.-W. Wei, "FIOWHM operator and its application to multiple attribute group decision making," Expert Systems with Applications, vol. 38, no. 4, pp. 2984-2989, 2011.

[37] Z. S. Xu, "An overview of methods for determining OWA weights," International Journal of Intelligent Systems, vol. 20, no. 8, pp. 843-865, 2005.

[38] Z. S. Xu, "Dependent uncertain ordered weighted aggregation operators," Information Fusion, vol. 9, no. 2, pp. 310-316, 2008.

[39] Y. J. Xu and H. M. Wang, "The induced generalized aggregation operators for intuitionistic fuzzy sets and their application in group decision making," Applied Soft Computing Journal, vol. 12, no. 3, pp. 1168-1179, 2012.

[40] Y. J. Xu and H. M. Wang, "Approaches based on 2-tuple linguistic power aggregation operators for multiple attribute group decision making under linguistic environment," Applied Soft Computing Journal, vol. 11, no. 5, pp. 3988-3997, 2011.

[41] R. R. Yager, "Centered OWA operators," Soft Computing, vol. 11, no. 7, pp. 631-639, 2007.

[42] M. Zarghami and F. Szidarovszky, "Revising the OWA operator for multi criteria decision making problems under uncertainty," European Journal of Operational Research, vol. 198, no. 1, pp. 259-265, 2009.

[43] L.-G. Zhou and H.-Y. Chen, "Generalized ordered weighted logarithm aggregation operators and their applications to group decision making," International Journal of Intelligent Systems, vol. 25, no. 7, pp. 683-707, 2010.

[44] L.-G. Zhou and H.-Y. Chen, "Continuous generalized OWA operator and its application to decision making," Fuzzy Sets and Systems, vol. 168, pp. 18-34, 2011.

[45] F. Herrera and L. Martinez, "An approach for combining linguistic and numerical information based on the 2-tuple 
fuzzy linguistic representation model in decision-making," International Journal of Uncertainty, Fuzziness and KnowledgeBased Systems, vol. 8, no. 5, pp. 539-562, 2000.

[46] Y.-J. Xu and Q.-L. Da, "Standard and mean deviation methods for linguistic group decision making and their applications," Expert Systems with Applications, vol. 37, no. 8, pp. 5905-5912, 2010. 


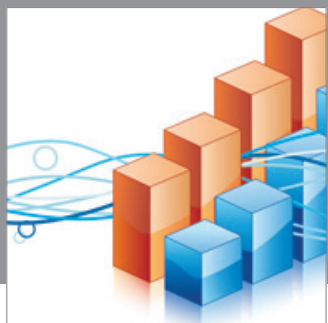

Advances in

Operations Research

mansans

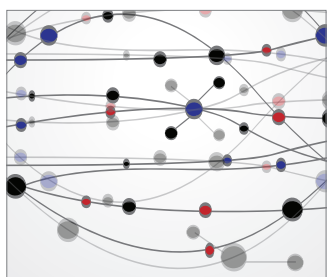

The Scientific World Journal
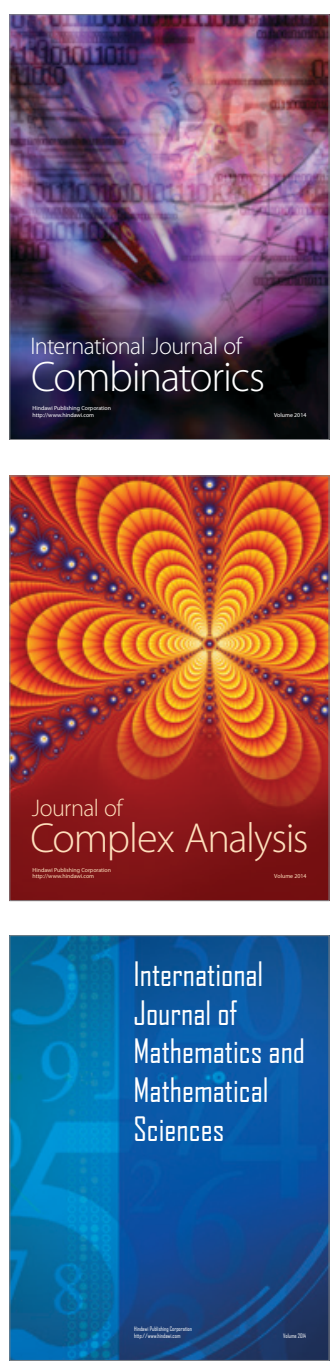
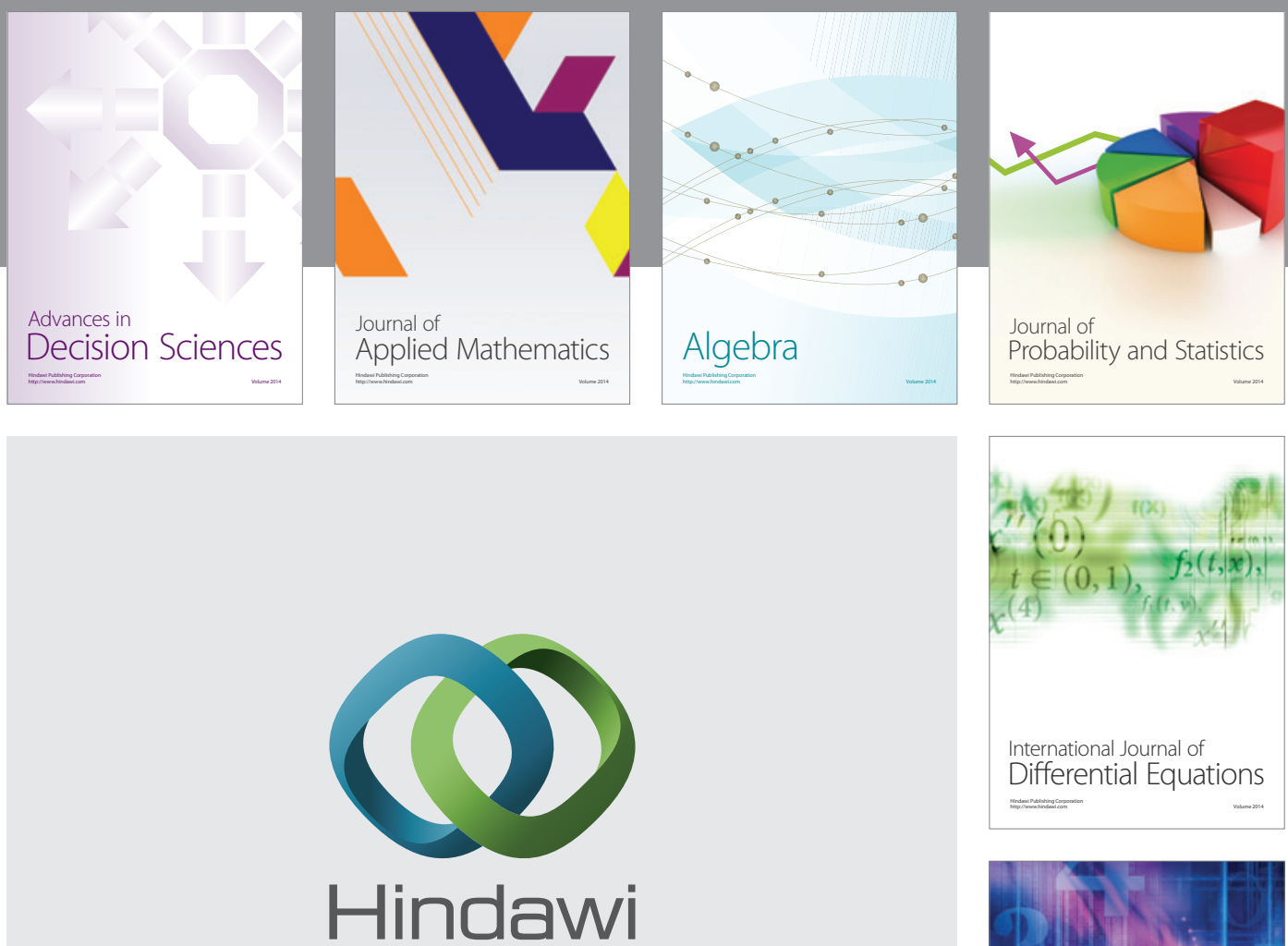

Submit your manuscripts at http://www.hindawi.com
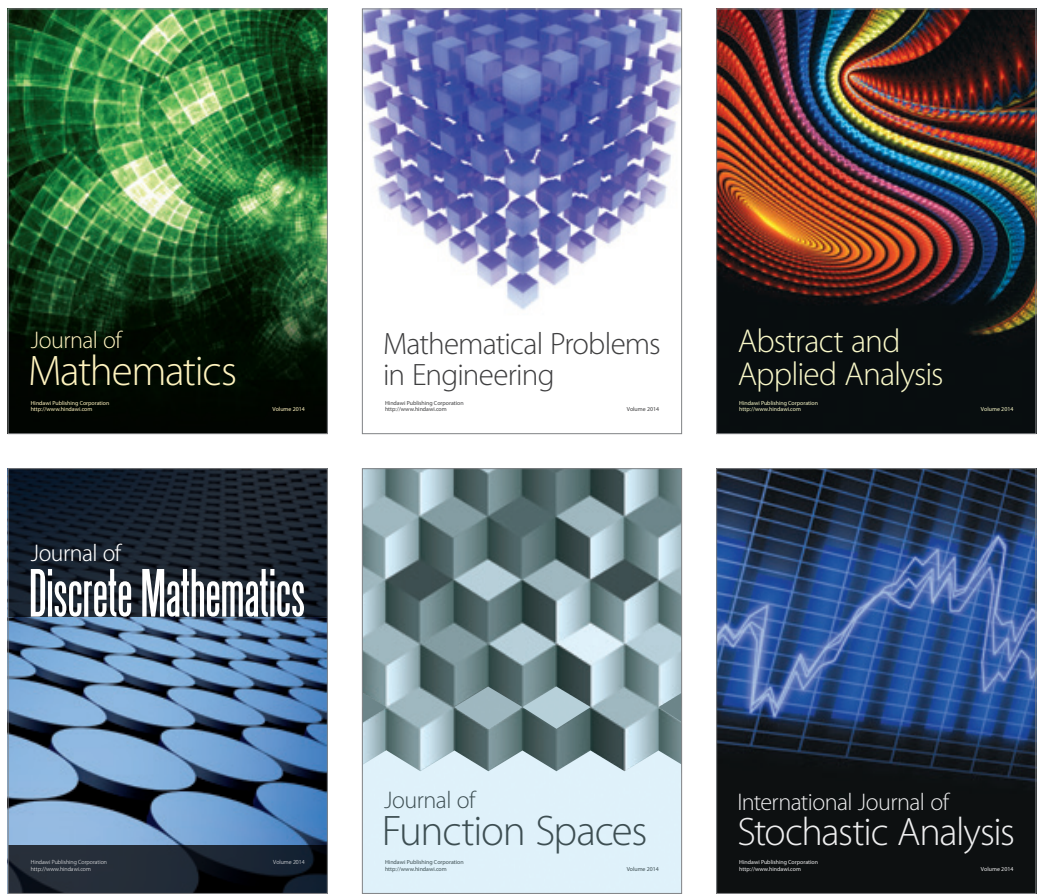

Journal of

Function Spaces

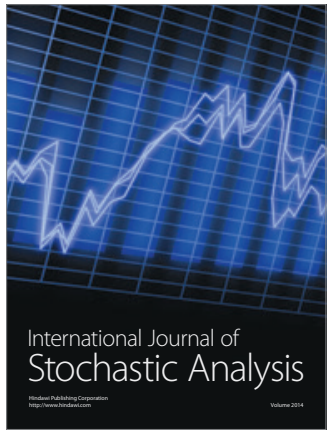

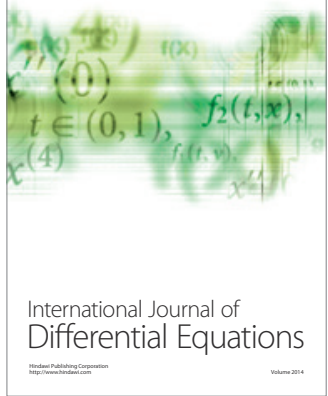
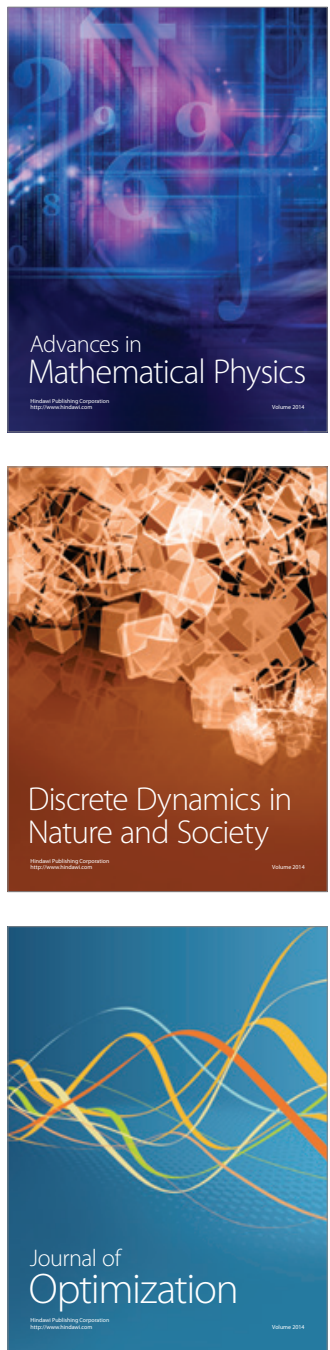